\title{
Caracterização física, química e sensorial de biscoitos confeccionados com farinha de semente de abóbora (FSA) e farinha de semente de baru (FSB) para celíacos
}

\section{Physical, chemical and sensory characteristics of cookies made of pumpkin seed flour (FSA) and seed flour baru (FSB) for celiacs}

Cristina Jesus Freitas'

Daniela Ribeiro Valente

Sabrina Pereira Cruz'

1 Instituto de Nutrição Josué de Castro, Departamento de Nutrição Básica e Experimental. Universidade Federal do Rio de Janeiro. Rio de Janeiro-RJ, Brasil.

Correspondência / Correspondence

Cristina de Jesus Freitas

E-mail: cristina@nutricao.ufri.br

\section{Resumo}

Objetivou-se utilizar farinha de semente de abóbora (FSA) e farinha de semente de baru (FSB) na confecção de biscoitos para celíacos e avaliar suas propriedades físicas, químicas, físico-químicas e sensoriais. Confeccionaram-se três tipos de biscoitos por modificação da formulação padrão (P), com substituição parcial do polvilho doce pela FSA (A) e FSB (B) em 10\%. As análises físicas dos biscoitos foram determinadas pelos procedimentos descritos no método 10-50D da American Association of Cereal Chemists. As características químicas e físico-químicas seguiram metodologias propostas pelo Instituto Adolfo Lutz. A avaliação sensorial foi realizada por dois testes: um de aceitabilidade (teste afetivo) com escala hedônica de 9 pontos, e outro de comparação múltipla (teste discriminativo), em blocos completos balanceados casualizados. Os dados foram submetidos a análise de variância e testes de média de Tukey e de Dunnett a 5\% de significância. Constatou-se que o biscoito B diferiu $(p<0,05)$ da fórmula controle, quanto a algumas características físicas como peso antes e pós-cocção, espessura, comprimento e largura pós-cocção. Os biscoitos diferiram $(\mathrm{p}<0,05)$ da formulação controle quanto ao rendimento, volume e índice de expansão, e também apresentaram maior valor para umidade, cinzas, lipídios e fibras. O biscoito B teve boa aceitação em todos os atributos. No teste discriminativo, o biscoito B obteve melhores notas. Conclui-se que a adição parcial de FSA e FSB melhora o valor nutricional dos biscoitos, pois aumenta a fibra alimentar, proteínas, minerais e lipídios, mas, sensorialmente, o FSB apresentou melhores resultados, demonstrando a possibilidade de utilização dessas farinhas em formulações de biscoitos para celíacos, em nível doméstico e industrial.

Palavras-chave: Biscoitos. Abóbora. Baru. Valor Nutricional. 


\section{Abstract}

The objective was to use pumpkin seed flour (FSA) and baru seed meal (FSB) in the manufacture of cookies for coeliacs, and evaluate their physical, chemical, physico-chemical and sensory characteristics. Three types of cookies were prepared by standard formulation modification $(\mathrm{P})$, with partial substitution of fresh flour FSA (A) and FSB (B) by 10\%. The physical analysis of biscuits were determined by the procedures described in 1050D method of the American Association of Cereal Chemists. The chemical and physicochemical characteristics followed methodologies proposed by Adolfo Lutz Institute. The sensory evaluation was performed by two tests: one of acceptability (affective test) with hedonic scale of 9 points, and other multiple comparison (discriminatory test), in a randomized complete block design balanced. Data were subjected to analysis of variance and Tukey test and Dunnett the 5\% significance level. It was found that biscuit B differ $(\mathrm{p}<0.05)$ in the control formula, for some physical characteristics such as weight before and after firing, thickness, length and width after firing. Cookies differ ( $\mathrm{p}$ $<0.05$ ) of the control formulation in terms of yield, and volume expansion ratio, and also showed higher value for moisture, ash, fat and fiber. Cookie B had good acceptance in all attributes. In the discriminatory test, the biscuit B got better grades. It is concluded that the partial addition of FSA and FSB improves the nutritional value of cookies, increases the dietary fiber, protein, minerals and lipids but, sensorily, the FSB showed better results, demonstrating the possibility of using such meal in formulations cookies for celiac in domestic and industrial level.

Keywords: Cookies. Pumpkin. Baru. Nutritional Value.

\section{Introdução}

A doença celíaca (DC) é uma intolerância permanente ao glúten, proteína contida em alguns cereais como trigo, centeio, cevada e aveia. ${ }^{1} \mathrm{O}$ índice de mortalidade no mundo em virtude dessa doença é aproximadamente duas vezes maior que o da mortalidade por outras causas, com um aumento que acontece predominantemente no primeiro ano depois do diagnóstico da enfermidade. A morte ocorre principalmente devido à presença de malignidades como linfoma intestinal. 
Pacientes com doença celíaca apresentam sintomas como diarreia, anorexia, desnutrição, distensão abdominal e perda de peso. A doença pode estar associada a inúmeras outras, tais como dermatite herpetiformis, osteoporose, epilepsia e diabetes mellitus tipo 1. O diagnóstico é baseado nas características clínicas, testes sorológicos de anticorpos específicos e biópsia intestinal. O tratamento dos pacientes celíacos consiste na exclusão do glúten da dieta deles por toda a vida, corrigindo os diferentes graus de desnutrição, anorexia, desidratação, intolerâncias alimentares, carências de vitaminas e minerais. ${ }^{2}$

$\mathrm{O}$ acesso a produtos elaborados com substitutos da farinha de trigo que apresentem valor nutricional e características sensoriais agradáveis são dificuldades encontradas pelos celíacos e pela indústria alimentícia. Os biscoitos estão entre os mais consumidos pela sociedade de uma maneira geral, o que é justificado pela facilidade de consumir e pelo custo acessível. Apesar da produção significativa de biscoitos no Brasil, a oferta desse produto isento de glúten é muito limitada. ${ }^{3,4}$

Existem inúmeros alimentos não convencionais que em geral não são utilizados na alimentação humana, mas que possuem grande quantidade de nutrientes. Os resíduos de alimentos minimamente processados e os resíduos de frutas e hortaliças utilizadas na indústria alimentícia são, geralmente, desprezados e poderiam ser utilizados para enriquecer alimentos. Exemplo disto é a semente de abóbora que é desprezada, porém estudos relatam diversos nutrientes encontrados nelas, tais como minerais, proteínas, lipídeos, fibras e antioxidantes, possibilitando seu uso na fortificação de alimentos e aumentando o valor nutricional dos produtos. ${ }^{3,5}$

Outro alimento que pode ser utilizado para enriquecer produtos são as amêndoas de baru, devido às suas propriedades funcionais, tais como fitoesteróis, antioxidantes e fibras alimentares. São boas fontes de proteínas, lipídios, sendo compostos principalmente por ácidos graxos monoinsaturados e poliinsaturados os quais estão relacionados com a diminuição dos riscos de doenças cardiovasculares.Também apresentam teor considerável de diversos minerais, destacando-se o ferro, cálcio, zinco e selênio, devido à importância dos dois primeiros na prevenção de carências nutricionais de relevância em Saúde Coletiva, e o zinco e selênio, pelas funções enzimáticas e reguladoras, como parte do sistema de defesa antioxidante do organismo. Outra positividade é o sabor agradável, pois por ser semelhante ao amendoim faz aumentar a aceitabilidade dos produtos. ${ }^{6,7}$

Estudos mostraram que tanto a semente de abóbora quanto a de baru apresentam fatores antinutricionais que podem interferir na biodisponibilidade dos nutrientes. No entanto, esses fatores podem ter sua ação inibida através de tratamento térmico adequado, como a torração, na forma de farinhas, o que ainda contribui para melhora do sabor e da textura..$^{5,7}$ 
A partir das evidências existentes em relação aos benefícios nutricionais da semente de abóbora e de baru, objetivou-se elaborar biscoitos para celíacos substituindo parcialmente o polvilho doce pela farinha de semente de abóbora e de baru, visando agregar valor nutricional ao produto, além de avaliar o efeito da adição dessas farinhas nas propriedades físicas,químicas, fisicoquímicas e sensoriais dos biscoitos.

\section{Material e Métodos}

\section{Material}

As farinhas de baru e abóbora foram obtidas por torrefação das sementes, conforme descrito no fluxograma 1 e 2 . Ao final do processo, foram obtidas as farinhas, sendo a de baru mais fina, e ambas de coloração clara e odor semelhante ao amendoim. A semente de baru foi fornecida pelo fabricante Belverde, sediado em Jardim Diamantina, Goiânia, GO.

\section{Semente de baru}

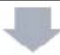

\section{Remover pele da} semente

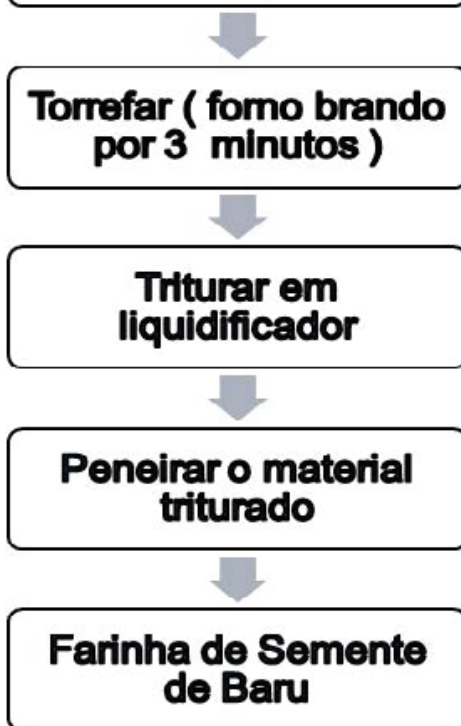

Figura 1. Fluxograma e obtenção da farinha de semente de baru. 


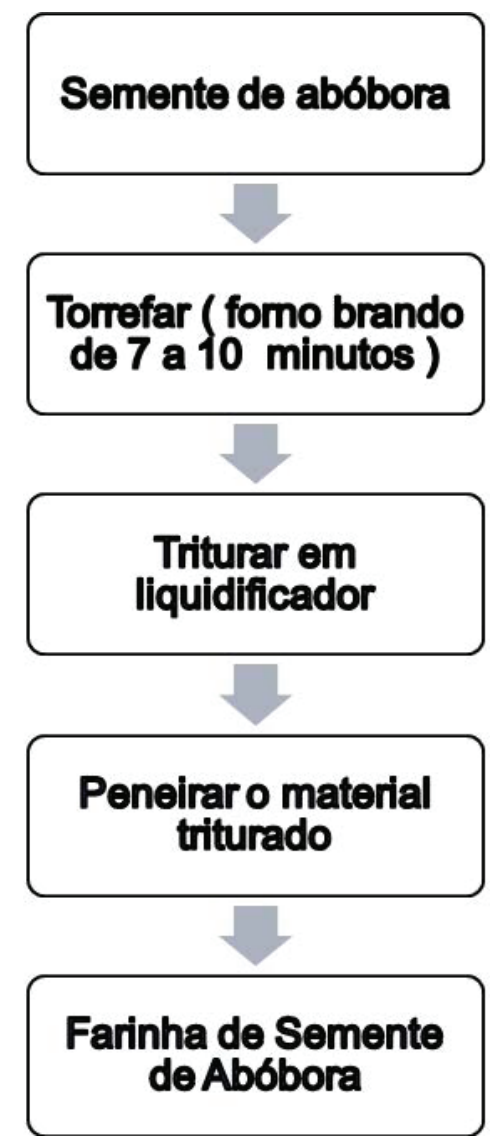

Figura 2. Fluxograma de obtenção da farinha de semente de abóbora.

\section{Formulação dos biscoitos tipo cookies}

Confeccionaram-se três tipos de biscoitos por modificação da formulação padrão, com substituição parcial do polvilho doce pela farinha de semente de abóbora (FSA) e farinha de semente de baru (FSB) em 10\%. Os biscoitos assim elaborados foram denominados A e B, respectivamente. Uma formulação básica foi elaborada, sem adição dessas farinhas, denominada padrão (P). A tabela 1 apresenta a proporção dos ingredientes utilizados para o preparo das formulações. As sementes utilizadas na formulação dos biscoitos foram obtidas no comércio do Rio de Janeiro (semente de abóbora) e em Goiânia (sementes de baru). Foram torrefadas por 7-10 minutos e três minutos, respectivamente, até obtenção de coloração dourada. Após, as sementes foram trituradas em liquidificador e peneiradas, para posterior utilização nas formulações descritas na tabela 1. Os ingredientes secos foram misturados e adicionou-se a margarina, gradualmente, até obtenção 
de uma massa homogênea. Em seguida, os biscoitos foram moldados com auxílio de formas e assados em forno moderado com temperatura de 150-180-C por 15 minutos. Os biscoitos foram resfriados à temperatura ambiente para a realização das análises física, físico-química e química.

Tabela 1. Formulação dos biscoitos elaborados. Rio de Janeiro-RJ, 2014.

\begin{tabular}{cccc}
\hline & \multicolumn{3}{c}{ Biscoitos } \\
\cline { 2 - 4 } Ingredientes $(\mathrm{g} \%)$ & Controle & $\mathrm{A}$ & $\mathrm{B}$ \\
\hline Açúcar mascavo & 11 & 11 & 11 \\
Polvilho doce & 30 & 20 & 20 \\
Araruta & 26 & 26 & 26 \\
Margarina & 27 & 1 & 1 \\
Fermento químico & 1 & 5 & 5 \\
Cacau em pó & 5 & 10 & - \\
FSA & - & - & 10
\end{tabular}

A-biscoito com FSA;B-biscoito com FSB

\section{Caracterização física dos biscoitos}

As análises físicas dos biscoitos controle $(\mathrm{P})$ e experimentais A e $\mathrm{B}$ compreenderam os procedimentos descritos no macrométodo 10-50D da American Association of Cereal Chemists (AACC), ${ }^{8}$ para determinação do peso, espessura, comprimento e largura antes e após a cocção. Os biscoitos foram pesados em balança digital marca ICEL. As análises foram conduzidas com dez biscoitos provenientes de uma mesma fornada amostrados de forma aleatória assim que foram resfriados em temperatura ambiente. A espessura, comprimento e largura dos biscoitos foram determinados com régua de escala milimetrada. O volume específico foi determinado pelo método de deslocamento de sementes de painço, seguido de três repetições para cada formulação. O volume específico foi calculado conforme a equação 1, abaixo:

Volume específico $\left(\mathrm{cm}^{3} / \mathrm{g}\right)=$ Volume do biscoito $\left(\mathrm{cm}^{3}\right) /$ peso do biscoito $(\mathrm{g})$

Volume do biscoito $=$ Volume sem o biscoito $\left(\mathrm{cm}^{3}\right)$ - Volume com biscoito 
A partir do peso pré e pós-cocção dos biscoitos também foi calculado o rendimento do produto (pós-cocção), ${ }^{9}$ segundo a equação 2 :

(Peso pós-cocção /Peso pré-cocção) $\times 100$

e o fator térmico, segundo a equação 3:

Peso pós cocção/Peso pré-cocção

O fator de expansão foi determinado pela razão entre os valores de diâmetro e espessura dos biscoitos, conforme método10-50D da AACC.

\section{Análise química e físico-química dos biscoitos}

As características químicas e físico-químicas foram determinadas por meio dos seguintes procedimentos: umidade em estufa a $105^{\circ} \mathrm{C}$ até peso constante, cinzas por incineração a $550^{\circ} \mathrm{C}$; lipídios, pelo método de extração por solvente (Método de Soxleht); o nitrogênio determinado pelo método de Kjeldahl e convertido em proteína bruta pelo fator 6,25, segundo AOAC, fibra insolúvel por método enzímico-gravimétrico, carboidratos (por diferença -NIFEXT), acidez titulável e determinação eletrométrica do $\mathrm{pH}$, conforme metodologias propostas pelo Instituto Adolfo Lutz. ${ }^{10}$ As análises de determinação de umidade, acidez titulável e pH foram realizadas em triplicata, e as demais, em duplicata.

\section{Análise sensorial dos biscoitos}

Esta pesquisa teve seu projeto avaliado e aprovado pelo Comitê de Ética em Pesquisa da Universidade Federal do Rio de Janeiro (números 1014/07 e 160). Os biscoitos foram submetidos a avaliação sensorial por dois testes: um de aceitabilidade (teste afetivo) e outro de comparação múltipla (teste discriminativo), aplicados em blocos completos balanceados casualizados. Também foi realizado o perfil dos provadores (figura 3).

A equipe foi composta por 62 provadores não treinados, selecionados de forma aleatória, pertencentes ao quadro da UFRJ com seu consentimento. O primeiro teste realizado foi o afetivo, onde os avaliadores informaram o quanto gostaram ou desgostaram de cada formulação preparada, para os atributos cor, aroma,textura e sabor utilizando escala hedônica estruturada de nove pontos, que variava de "gostei muitíssimo" (pontuação máxima) a "desgostei muitíssimo" (pontuação 
mínima). O segundo teste realizado foi o discriminativo, no qual os avaliadores compararam as formulações A e B com a formulação controle para o aspecto global, dando notas que variavam de 9 (extremamente melhor que o padrão) a 1 (extremamente pior que o padrão). ${ }^{10}$

\section{Perfil do consumidor}

Nome:

Sexo: ( )M ( )F

Idade: ( ) $<18$ anos ( ) $18-25$ anos ( ) $26-40$ anos ( ) acima de 40

Grau de escolaridade: ( ) Ensino fundamental ( ) Ensino médio ( ) Superior ( ) Pósgraduação

Frequência de consumo:

\begin{tabular}{|l|l|l|l|l|}
\hline Alimentos & Nunca & Diário & Semanal & Mensal \\
\hline $\begin{array}{l}\text { Refrigerante } \\
\text { Bolo }\end{array}$ & & & & \\
\hline Biscoito & & & & \\
\hline Frutas & & & & \\
\hline
\end{tabular}

Teste de aceitação

Por favor, prove e avalie, da esquerda para a direita, o quanto você gostou ou desgostou da amostra, utilizando a escala abaixo:

9-Gostei muitíssimo

8-Gostei muito

7-Gostei moderadamente

6-Gostei ligeiramente

5-Não gostei/Nem desgostei

4-Desgostei ligeiramente

3-Desgostei moderadamente

2-Desgostei muito

1-Desgostei muitíssimo

Amostra:

Amostra:

Cor:

Aroma:

Textura:

Sabor:

Cor:

Aroma:

Textura:

Sabor:
Nome

Data:

COMPARAÇÃO

MÚLTIPLA

Vocệ está receendo uma amostra padrão $(P)$ e 2 amostras codificadas.Compare cada amostra, da esquerda para a direita, com o padrão e identifique se é melhor,igual ou pior que o padrão, dando as notas abaixo.

9- Extremamente melhor que o padrão

8-Muito melhor que o padrão

7-Moderadamente melhor que o padrão

6- Ligeir armente melhor que o padr ão

5- Igual ao padrão

4-Lıgeıramente pıor que o padräo

3-Moderadamente pior que o padrão

2-Muito pior que o padrão

1-Extremamente pior que o padrão

Amostra

Amostra

Figura 3. Ficha de identificação do consumidor e dos testes afetivo e discriminativo. 


\section{Análises Estatísticas}

Os resultados das caracterizações físicas, químicas, físico-químicas e os testes sensoriais foram analisados através de análise de variância e pelos testes de média: teste de Tukey e Dunnett, específicos para cada análise sensorial em nível de significância de 5\% utilizando o programa Statistica.

\section{Resultados e discussão}

\section{Caracterização física dos biscoitos}

Na tabela 2, estão os resultados das análises físicas dos biscoitos das diferentes formulações produzidas com substituição parcial do polvilho doce pela FSA ou FSB.

Tabela 2. Médias das avaliações físicas dos biscoitos elaborados. Rio de Janeiro-RJ, 2014.

\begin{tabular}{cccc}
\hline \multirow{2}{*}{ Determinações } & \multicolumn{3}{c}{ Biscoitos } \\
\cline { 2 - 4 } & Controle & $\mathrm{A}$ & $\mathrm{B}$ \\
\hline Peso antes-cocção $(\mathrm{g})$ & $5,91 \mathrm{a}$ & $6,07 \mathrm{a}$ & $7,02 \mathrm{~b}$ \\
pós-cocção & $5,4 \mathrm{a}$ & $5,75 \mathrm{a}$ & $6,74 \mathrm{~b}$ \\
\hline Altura antes-cocção $(\mathrm{cm})$ & $0,63 \mathrm{a}$ & $0,66 \mathrm{a}$ & $0,73 \mathrm{a}$ \\
pós-cocção & $0,69 \mathrm{a}$ & $0,79 \mathrm{ab}$ & $0,88 \mathrm{~b}$ \\
\hline Comprimento antes-cocção $(\mathrm{cm})$ & $2,71 \mathrm{ab}$ & $2,68 \mathrm{a}$ & $2,76 \mathrm{~b}$ \\
pós-cocção & $2,66 \mathrm{a}$ & $2,69 \mathrm{a}$ & $2,83 \mathrm{~b}$ \\
\hline Largura antes-cocção $(\mathrm{cm})$ & $2,71 \mathrm{ab}$ & $2,67 \mathrm{a}$ & $2,75 \mathrm{~b}$ \\
pós-cocção & $2,65 \mathrm{a}$ & $2,69 \mathrm{a}$ & $2,79 \mathrm{~b}$ \\
\hline Fator térmico & $0,91 \mathrm{a}$ & $0,95 \mathrm{~b}$ & $0,96 \mathrm{~b}$ \\
Rendimento $(\%)$ & $91,4 \mathrm{a}$ & $94,7 \mathrm{~b}$ & $96,3 \mathrm{~b}$ \\
Volume (mL/g) & $1,69 \mathrm{a}$ & $4,90 \mathrm{~b}$ & $3,77 \mathrm{~b}$ \\
Fator expansão & $106,9 \mathrm{a}$ & $124 \mathrm{~b}$ & $127,6 \mathrm{~b}$ \\
\hline
\end{tabular}

Médias seguidas de letras iguais na horizontal não diferem entre si. $\mathrm{p}>0.05$

A-biscoito com FSA; B-biscoito com FSB 
O biscoito B diferiu $(\mathrm{p}<0,05)$ da fórmula controle, para as determinações de peso antes e pós-cocção e espessura, comprimento e largura pós-cocção, enquanto que o biscoito A não diferiu nestes aspectos.

A maior variação de peso observada no biscoito B pode indicar maior capacidade de retenção de água pelos componentes da massa do biscoito após a adição da FSB. Nota-se também que após a cocção, o biscoito FSB apresentou maior espessura, largura e comprimento, indicando que a adição de FSB pode ter interferido nas características físicas do biscoito, fazendo com que a massa sofresse maior espaçamento durante a cocção, aumentando por consequência seu rendimento.

O fator de expansão foi maior $(\mathrm{p}<0,05)$ para os biscoitos A e $\mathrm{B}$ em relação ao biscoito $\mathrm{P}$ controle (tabela 2). O fator de expansão está relacionado com a capacidade dos ingredientes em absorver água, e é utilizado como indicador de qualidade. Os biscoitos elaborados com alto teor de fibras geralmente apresentam diminuição do fator de expansão, o que não ocorreu neste trabalho. $\mathrm{O}$ mesmo resultado foi encontrado no estudo de Moura \& Spier. ${ }^{4}$

É importante destacar que os biscoitos A e B não diferiram ( $p>0,05)$ quanto ao rendimento e volume, porém diferiram $(\mathrm{p}<0,05)$ da formulação controle, indicando que ao substituir parcialmente o polvilho doce por essas farinhas tem-se melhores resultados no que se relacionada ao rendimento, o que é considerado um aspecto positivo para ser utilizado pelas indústrias de alimentos.

\section{Caracterização química e físico-química dos biscoitos}

A composição química dos biscoitos elaborados está apresentada na tabela 3.

Tabela 3. Médias das características químicas e físico-químicas dos biscoitos elaborados. Rio de Janeiro-RJ, 2014.

Biscoitos

\begin{tabular}{|c|c|c|c|}
\hline Determinações $\quad(\mathrm{g} \%)$ & Controle & A & B \\
\hline Umidade & $3,82 \mathrm{a}$ & $4,86 \mathrm{~b}$ & $6,50 \mathrm{c}$ \\
\hline Cinzas & $1,51 \mathrm{a}$ & $1,93 \mathrm{c}$ & $1,76 b$ \\
\hline Lipídios & $23,79 \mathrm{a}$ & $27,30 \mathrm{~b}$ & $26,37 \mathrm{~b}$ \\
\hline Proteínas & $1,3 \mathrm{a}$ & $3,92 \mathrm{~b}$ & $3,63 \mathrm{~b}$ \\
\hline Carboidratos & $67,89 \mathrm{a}$ & $57,09 \mathrm{~b}$ & $57,97 \mathrm{~b}$ \\
\hline
\end{tabular}




$\begin{array}{cccc}\text { Fibras } & 1,69 \mathrm{a} & 4,90 \mathrm{~b} & 3,77 \mathrm{~b} \\ \text { Acidez titulável (mL.g-1) } & 2,79 \mathrm{a} & 3,22 \mathrm{a} & 2,42 \mathrm{a} \\ \mathrm{pH} & 6,35 \mathrm{a} & 6,87 \mathrm{~b} & 6,77 \mathrm{ab}\end{array}$

Médias seguidas de letras iguais na horizontal não diferem entre si. $\mathrm{p}>0.05$

A-biscoito com FSA; B-biscoito com FSB

O teor de umidade dos biscoitos foi menor que 6,50\%, estando de acordo com o padrão estipulado pela CNNPA, ${ }^{11}$ que deve ser menor que $14 \%$. Os biscoitos A e B apresentaram maior teor de umidade, cinzas, lipídios e fibras, comparados ao biscoito controle. O maior teor de lipídios dos biscoitos $\mathrm{A}$ e $\mathrm{B}$ está relacionado à grande quantidade do ácido graxo poliinsaturado $\omega$-6 (ácido linoleico) presente na semente de abóbora e de baru, além do ácido graxo monoinsaturado $\omega-9$ (oleico), que também compõe as frações lipídicas da semente de baru.

Essa composição em ácidos graxos mono e poliinsaturado é importante para a saúde, uma vez que esses ácidos contribuem para a redução das frações de lipoproteína de baixa densidade (LDL) e de muito baixa densidade (VLDL), responsáveis pelo aumento do colesterol sérico. ${ }^{4,6} \mathrm{~A}$ quantidade de cinzas foi maior nos biscoitos elaborados com semente de abóbora, devido ao alto teor de minerais presentes nesta semente. ${ }^{4}$ Houve expressiva elevação do teor de fibras nos biscoitos A e B em relação ao controle,o que está diretamente relacionado ao alto teor de fibra dessas farinhas.

Segundo Freitas \& Naves, ${ }^{6}$ a semente de baru constitui boa fonte de fibras alimentares, com predominância de fibras insolúveis. Teores consideráveis de fibras insolúveis contribuem para o aumento do bolo fecal e prevenção de problemas intestinais, valorizando ainda mais esses alimentos na promoção da saúde.

Diversos estudos mostram que a semente de abóbora também apresenta alto teor de fibras alimentares, e tem efeito laxativo, proporcionado pelas fibras insolúveis presentes na semente de abóbora. ${ }^{12}$ Ambos os produtos A e B são considerados fontes de fibra alimentar segundo a ANVISA..$^{13}$

Quanto às análises físico-químicas, ainda na tabela 3, todos os biscoitos elaborados apresentaram valores semelhantes para acidez titulável, não havendo diferença significativa entre eles. Já os valores de $\mathrm{pH}$ encontrados mostraram que o biscoito A apresentou maior $(\mathrm{p}<0,05)$ valor, quando comparado ao controle e não houve diferença entre o biscoito A e B para tal determinação.

Os valores de pH e acidez titulável fornecem informação quanto à qualidade das farinhas, visto que quanto menor o valor de $\mathrm{pH}$ e maior o valor de acidez titulável, maior é a conversão dos ácidos graxos de cadeia longa em ácidos orgânicos de cadeia curta, os quais conferem sabor e odor desagradáveis aos produtos. ${ }^{14}$ Portanto, a farinha de semente de abóbora e a de baru se apresentam adequadas para a elaboração dos biscoitos. 


\section{Análise Sensorial}

\section{Perfil dos provadores}

A figura 4 expressa que 74,19\% dos avaliadores são do sexo feminino e 25,80 \%, do masculino, predominantemente adulta com faixa etária entre 18 a 25 anos. O grau de escolaridade dominante foi ensino superior. Em relação à frequência de consumo alimentar, foram considerados os atributos "nunca" , "diário", "semanal" e "mensal". Neste grupo, prevaleceu a frequência de consumo semanal tanto para o biscoito como para os outros produtos industrializados pesquisados (refrigerante e bolo).

Os resultados indicam, portanto, que estes produtos encontram-se frequentemente presentes na alimentação dos provadores. Em contrapartida, para o consumo de frutas prevaleceu a frequência de consumo diário.
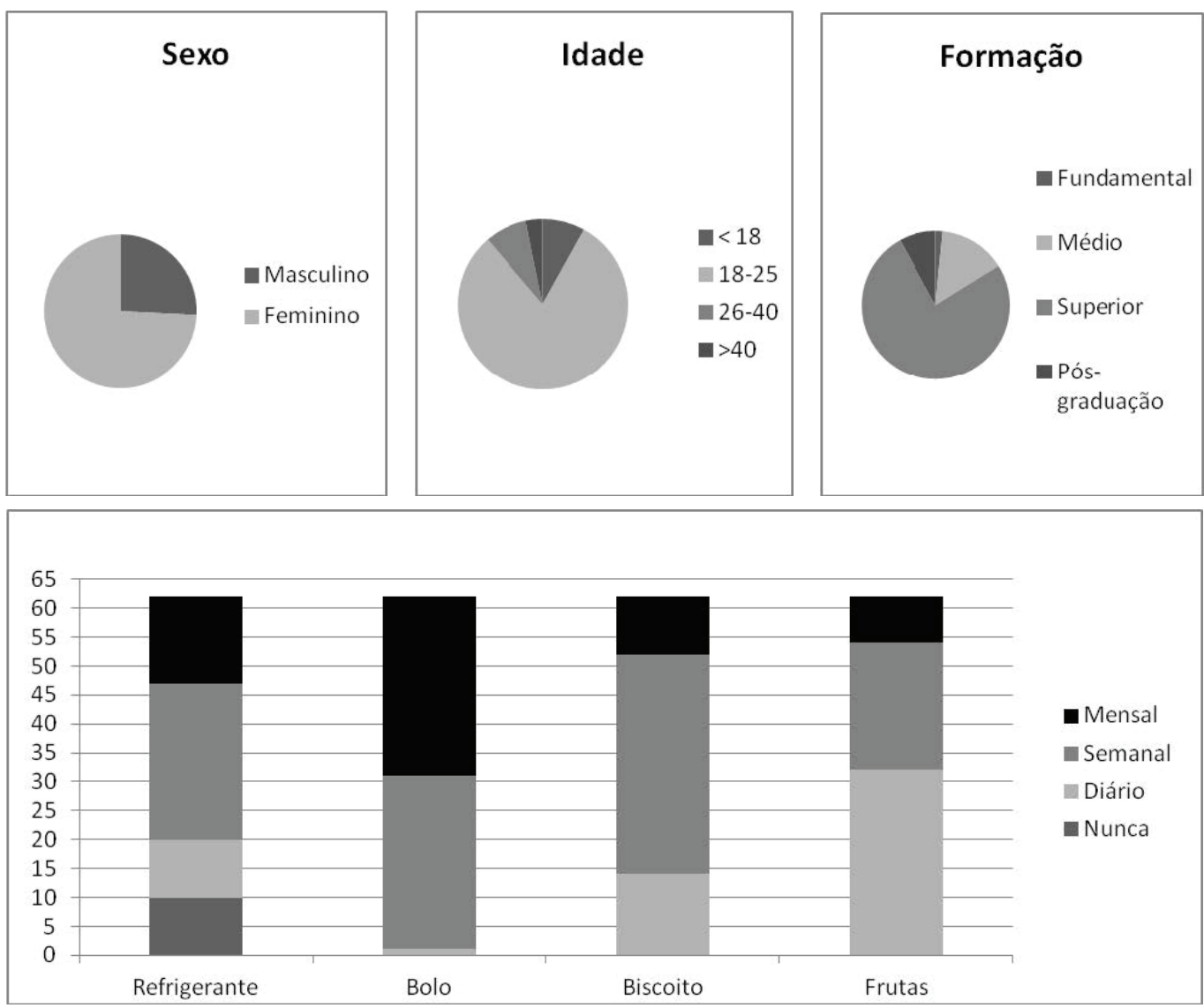

Figura 4. Perfil dos consumidores dos biscoitos elaborados 


\section{Testes sensoriais dos biscoitos}

A distribuição dos provadores pelos valores hedônicos para os produtos experimentais encontrase na figura 5 .
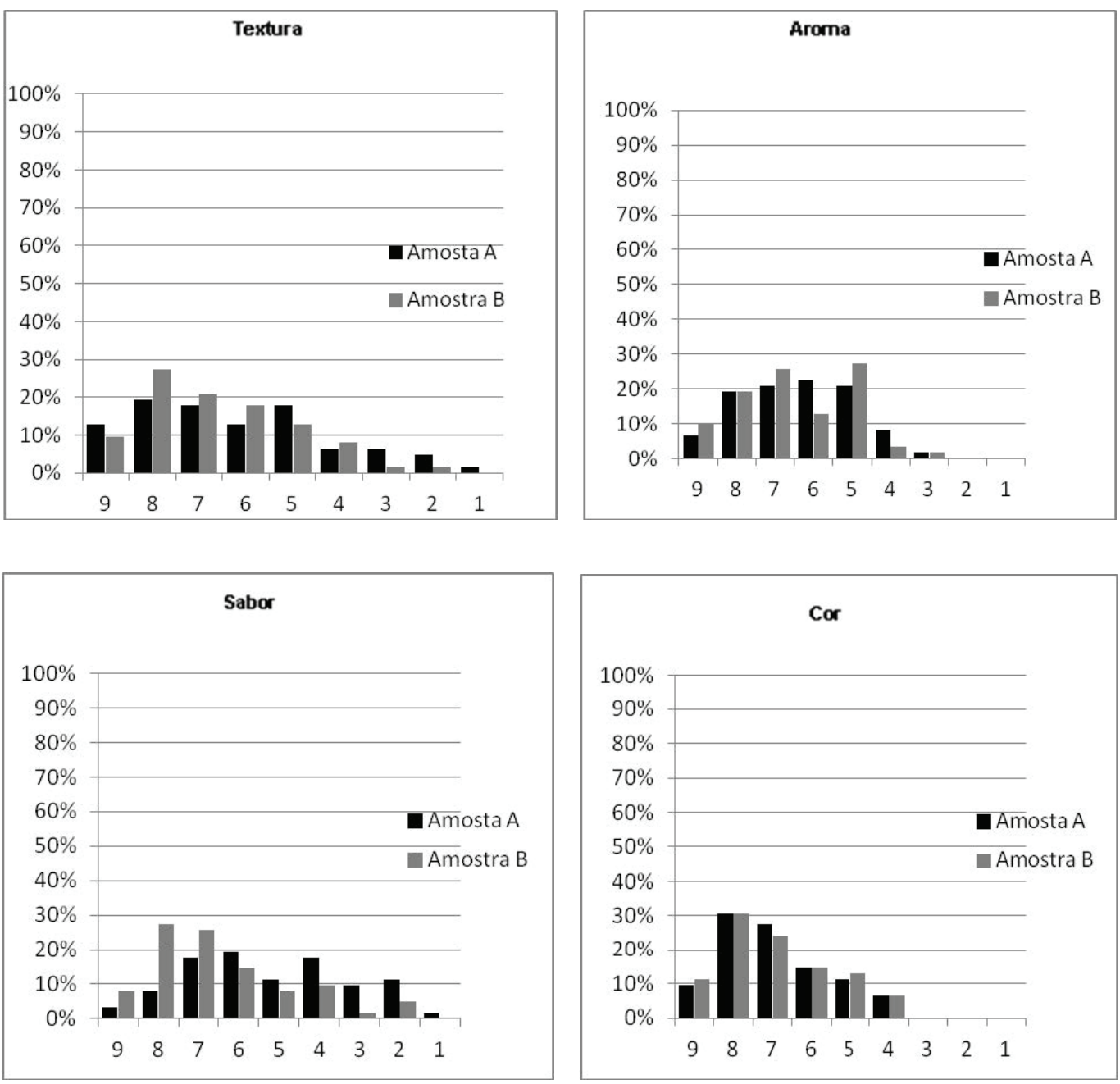

$\mathrm{A}=$ Farinha de semente de abóbora e $\mathrm{B}=$ Farinha de semente de baru

Figura 5. Distribuição dos provadores pelos valores hedônicos para os atributos dos produtos avaliados 
As médias das notas atribuídas no teste afetivo de escala hedônica pelos provadores às formulações de biscoitos quanto à preferência sensorial dos atributos textura, aroma, sabor e cor estão apresentadas na tabela 4. O biscoito B obteve a maior média quanto ao atributo sabor, e para os outros atributos os biscoitos A e B não diferiram entre si. Isso também pode ser observado na figura 5, na qual se demonstra a preferência dos provadores quanto aos quatro atributos avaliados. De uma maneira geral, pode-se dizer que mais de $62 \%$ dos provadores atribuíram notas acima de 5 (não gostei/nem desgostei) para todos os atributos, no biscoito B. No entanto, o mesmo não ocorreu com o biscoito A, onde apenas $48 \%$ dos provadores atribuíram notas acima de 5 para o atributo "sabor", indicando que este atributo foi o que mais diferenciou os biscoitos, revelando que o biscoito B apresentou melhor sabor do que o biscoito A.

Tabela 4. Médias do teste afetivo - escala hedônica para os biscoitos avaliados. Rio de JaneiroRJ, 2014.

\begin{tabular}{ccc}
\hline Atributos & A & B \\
\hline Textura & $6,18 \mathrm{a}$ & $6,64 \mathrm{a}$ \\
Sabor & $5,14 \mathrm{a}$ & $6,53 \mathrm{~b}$ \\
Cor & $6,93 \mathrm{a}$ & $6,94 \mathrm{a}$ \\
Aroma & $6,37 \mathrm{a}$ & $6,55 \mathrm{a}$ \\
\hline
\end{tabular}

Médias seguidas de letras iguais na horizontal não diferem entre si. p>0,05;

$\mathrm{A}=$ Farinha de semente de abóbora e $\mathrm{B}=$ Farinha de semente de baru

Na tabela 5, apresentam-se os valores médios relativos às pontuações atribuídas no teste discriminativo, para o aspecto global dos biscoitos A e B comparados ao padrão, onde o biscoito B obteve a maior média.

Tabela 5. Médias dos valores do teste discriminativo - comparação múltipla dos biscoitos avaliados. Rio de Janeiro-RJ, 2014.

\begin{tabular}{ccc}
\hline Atributos & $\mathrm{A}$ & $\mathrm{B}$ \\
\hline Aspecto Global & $5,23 \mathrm{a}$ & $6,63 \mathrm{~b}$ \\
\hline
\end{tabular}

Médias seguidas de letras iguais na horizontal não diferem entre si. $\mathrm{p}>0,05$;

$\mathrm{A}=$ Farinha de semente de abóbora e $\mathrm{B}=$ Farinha de semente de baru 
Tabela 6. Índices de Aceitabilidade (\%) para os biscoitos avaliados. Rio de Janeiro-RJ, 2014.

\begin{tabular}{ccc}
\hline Atributos & A & B \\
\hline Textura & $68,63 \mathrm{a}$ & $73,77 \mathrm{a}$ \\
Sabor & $57,16 \mathrm{a}$ & $72,55 \mathrm{~b}$ \\
Cor & $77,06 \mathrm{a}$ & $77,11 \mathrm{a}$ \\
Aroma & $70,78 \mathrm{a}$ & $72,77 \mathrm{a}$ \\
\hline
\end{tabular}

Médias seguidas de letras iguais na horizontal não diferem entre si. $\mathrm{p}>0,05$;

$\mathrm{A}=$ Farinha de semente de abóbora e $\mathrm{B}=$ Farinha de semente de baru

O índice de aceitabilidade dos biscoitos A e B está apresentado na tabela 6. O biscoito B apresentou boa aceitação em todos os atributos avaliados, conferindo-lhe boa aceitação. Entretanto o biscoito A não atingiu o índice de aceitabilidade mínimo de 70\% para os atributos textura e sabor.

De um modo geral, os resultados revelam que os provadores consideraram o biscoito B melhor do que o biscoito A.

\section{Conclusão}

Conclui-se que a adição de FSA e FSB, em substituição parcial ao polvilho doce, melhoram o valor nutricional dos biscoitos para celíacos pois aumentam o teor de fibra alimentar, proteínas, minerais e lipídios porém, sensorialmente, o biscoito B contendo FSB apresentou melhores resultados, mostrando que esta farinha pode substituir parcialmente as farinhas tradicionais em formulações de biscoitos para celíacos, tanto em nível doméstico quanto industrial.

\section{Referências}

1. Silva PC, Almeida PDV, Azevedo LR, Grégio AMT, Machado MAN, Lima AAS. Doença Celíaca: revisão. Clin. Pesq. Odontol 2006; 2(5-6): 401-6.

2. Nascimento KO, Barbosa MIMJ, Takeiti, CY. Doença Celíaca: síntomas, diagnóstico e tratamento nutricional. Saúde em Revista 2012; 12(30):53-63.

3. Mauro AK, Silva VLM, Freitas MCJ. Caracterização física, química e sensorial de cookies confeccionados com Farinha de Talo de Couve (FTC) e Farinha de Talo de Espinafre (FTE) ricas em fibra alimentar. Ciênc. Tecnol. Aliment. 2010; 30(3):719-28. 
4. Moura FA, Spier F, Zavareze ER, Dias ARG, Elias MC. Biscoitos tipo “cookie” elaborados com diferentes frações de semente de abóbora (curcubita maxima). Alim. Nutr. 2010; 21(4):579-85.

5. Del-Vechio G, Corrêa AD, Abreu MP, Santos CD. Efeito do tratamento térmico em sementes de abóboras (cucurbita spp.) sobre os níveis de fatores antinutricionais e/ou tóxicos. Ciênc. Agrotec. 2005; 29(2):369-76.

6. Freitas JB, Naves MMV. Composição química de nozes e sementes comestíveis e sua relação com a nutrição e saúde. Revista de Nutrição 2010; 23(2):269-79.

7. Vera R, Souza ERB. Baru. Rev. Bras. Frutic 2009; 31(1):001.

8. American Association of Cereal Chemists. Approved methods of the American Association of Cereal Chemists. 9 ed. Saint Paul: AACC; 1995.

9. Araújo MOD, Guerra IMM. Alimentos per capita. Natal: Universitária; 1992.

10. Instituto Adolfo Lutz. Métodos físico-químicos para análise de alimentos: normas analíticas do Instituto Adolfo Lutz. 4 ed. [1. ed. Digital]. Brasília: ANVISA; 2008.

11. Brasil. Comissão Nacional de Normas e Padrões para Alimentos. Resolução 12/78 - Alimentos e bebidas: 47 padrões de identidade e qualidade. In: Associação Brasileira das Indústrias de Alimentação. Compêndio de resoluções da CNNPA. São Paulo: ABIA; 1978.

12. Pumar M, Freitas MCJ, Cerqueira PM, Santangelo SB. Avaliação do efeito fisiológico da farinha de semente de abóbora (Cucurbita maxima, L.) no trato intestinal de ratos. Ciênc. Tecnol. Aliment. 2008; 28(Supl.):7-13.

13. Brasil. Portaria no 27 de 13 de janeiro de 1998. Aprova Regulamento Técnico referente à Informação Nutricional Complementar (declarações relacionadas ao conteúdo de nutrientes). Diário Oficial da União 16 jan. 1998

14. Silva JS. Barra de cereais elaboradas com farinha de semente de abóbora [dissertação]. Lavras, MG: Programa de Pós Graduação em Agroquímica, Universidade Federal de Lavras; 2012.

Recebido: 14/10/2014

Revisado: 20/11/2014

Aprovado: 25/11/2014 